Article

\title{
Characteristics of Precipitation Diurnal Cycle over a Mountainous Area of Sumatra Island including MJO and Seasonal Signatures Based on the 15-Year Optical Rain Gauge Data, WRF Model and IMERG
}

\author{
Marzuki Marzuki ${ }^{1, *} \oplus$, Helmi Yusnaini ${ }^{1}$, Ravidho Ramadhan ${ }^{1,2}$, Fredolin Tangang ${ }^{3}$, Abdul Azim Bin Amirudin ${ }^{3}$, \\ Hiroyuki Hashiguchi ${ }^{4}$, , Toyoshi Shimomai ${ }^{5}$ and Mutya Vonnisa ${ }^{1}$ \\ check for \\ updates \\ 1 Department of Physics, Universitas Andalas, Padang 25163, Indonesia; helmiyusnaini@gmail.com (H.Y.); \\ ravidhoramadhan20@gmail.com (R.R.); mutyavonnisa@sci.unand.ac.id (M.V.) \\ 2 Department of Physics, Universitas Gadjah Mada, Yogyakarta 55281, Indonesia \\ 3 Department of Earth Sciences and Environment, Faculty of Science and Technology, Universiti Kebangsaan \\ Malaysia, Bangi 43600, Selangor, Malaysia; tangang@ukm.edu.my (F.T.); \\ p94165@siswa.ukm.edu.my (A.A.B.A.) \\ 4 Research Institute for Sustainable Humanosphere (RISH), Kyoto University, Gokasho, Uji, Kyoto 611-0011, \\ Japan; hasiguti@rish.kyoto-u.ac.jp \\ 5 Department of Electronic and Control Systems Engineering, Shimane University, Shimane 690-0823, Japan; \\ shimomai@ecs.shimane-u.ac.jp \\ * Correspondence: marzuki@sci.unand.ac.id
}

Citation: Marzuki, M.; Yusnaini, H.

Ramadhan, R.; Tangang, F.;

Amirudin, A.A.B.; Hashiguchi, H.;

Shimomai, T.; Vonnisa, M.

Characteristics of Precipitation

Diurnal Cycle over a Mountainous

Area of Sumatra Island including

MJO and Seasonal Signatures Based

on the 15-Year Optical Rain Gauge

Data, WRF Model and IMERG.

Atmosphere 2022, 13, 63. https://

doi.org/10.3390/atmos13010063

Academic Editors: Tomeu Rigo,

Zuohao Cao, Huaqing Cai and

Xiaofan Li

Received: 15 November 2021

Accepted: 28 December 2021

Published: 30 December 2021

Publisher's Note: MDPI stays neutral with regard to jurisdictional claims in published maps and institutional affiliations.

Copyright: (c) 2021 by the authors. Licensee MDPI, Basel, Switzerland. This article is an open access article distributed under the terms and conditions of the Creative Commons Attribution (CC BY) license (https:// creativecommons.org/licenses/by/ $4.0 /)$.

\begin{abstract}
In this study we investigate the characteristics of the diurnal precipitation cycle including the Madden-Julian oscillation (MJO) and seasonal influences over a mountainous area in Sumatra Island based on the in situ measurement of precipitation using the optical rain gauge (ORG). For comparison with ORG data, the characteristics based on the Global Precipitation Measurement (GPM) mission (IMERG) and Weather Research and Forecasting (WRF) simulations were also investigated. Fifteen years of ORG data over a mountainous area of Sumatra, namely, at Kototabang $\left(100.32^{\circ} \mathrm{E}\right.$, $0.20^{\circ} \mathrm{S}$ ), were analyzed to obtain the characteristics of the diurnal cycle of precipitation in this region. The diurnal cycle of precipitation presented a single peak in the late afternoon, and the peak time difference was closely related to the rain event duration. The MJO acts to modulate the diurnal amplitude but not the diurnal phase. A high precipitation amount (PA) and frequency (PF) were observed during phases 2,3 , and 4 , along with an increase in the number of longer-duration rain events, but the diurnal phase was similar in all MJO phases. In terms of season, the highest PA and PF values were observed during pre-southwest and pre-northeast monsoon seasons. WRF simulation reproduced the diurnal phase correctly and more realistically than the IMERG products. However, it largely overestimated the amplitude of the diurnal cycle in comparison with ORG. These disagreements could be related to the resolution and quality of IMERG and WRF data.
\end{abstract}

Keywords: diurnal cycle; Kototabang; Sumatra; optical rain gauge; IMERG; WRF

\section{Introduction}

The estimation of precipitation at high altitudes in Indonesia, including Sumatra, is challenging because in situ measurements remain scarce. Sumatra is one of the largest islands in Indonesia, and is directly adjacent to the Indian Ocean (see Figure 1). It is considered important in global atmospheric circulation because its position is almost perpendicular to the propagation of winds and clouds from the Indian Ocean [1-3]. The combination of mesoscale variability with topography and the coastline controls diabatic heating in Indonesia, including Sumatra [4]. The Barisan mountain range in Sumatra, with an average altitude of $2000 \mathrm{~m}$, plays an essential role in the convection process in this 
region $[5,6]$. Sumatra's topography induces convection in Sumatra and the surrounding area [7-9]. Interestingly, rainfall characteristics on both sides of the Barisan mountains are different [10], with more frequent rainfall in the western part of the Barisan mountains, resulting in a greater amount of rain in this area than on the eastern side. However, the precipitation intensity in the western part of the Barisan mountains is smaller than that on the eastern side [11].

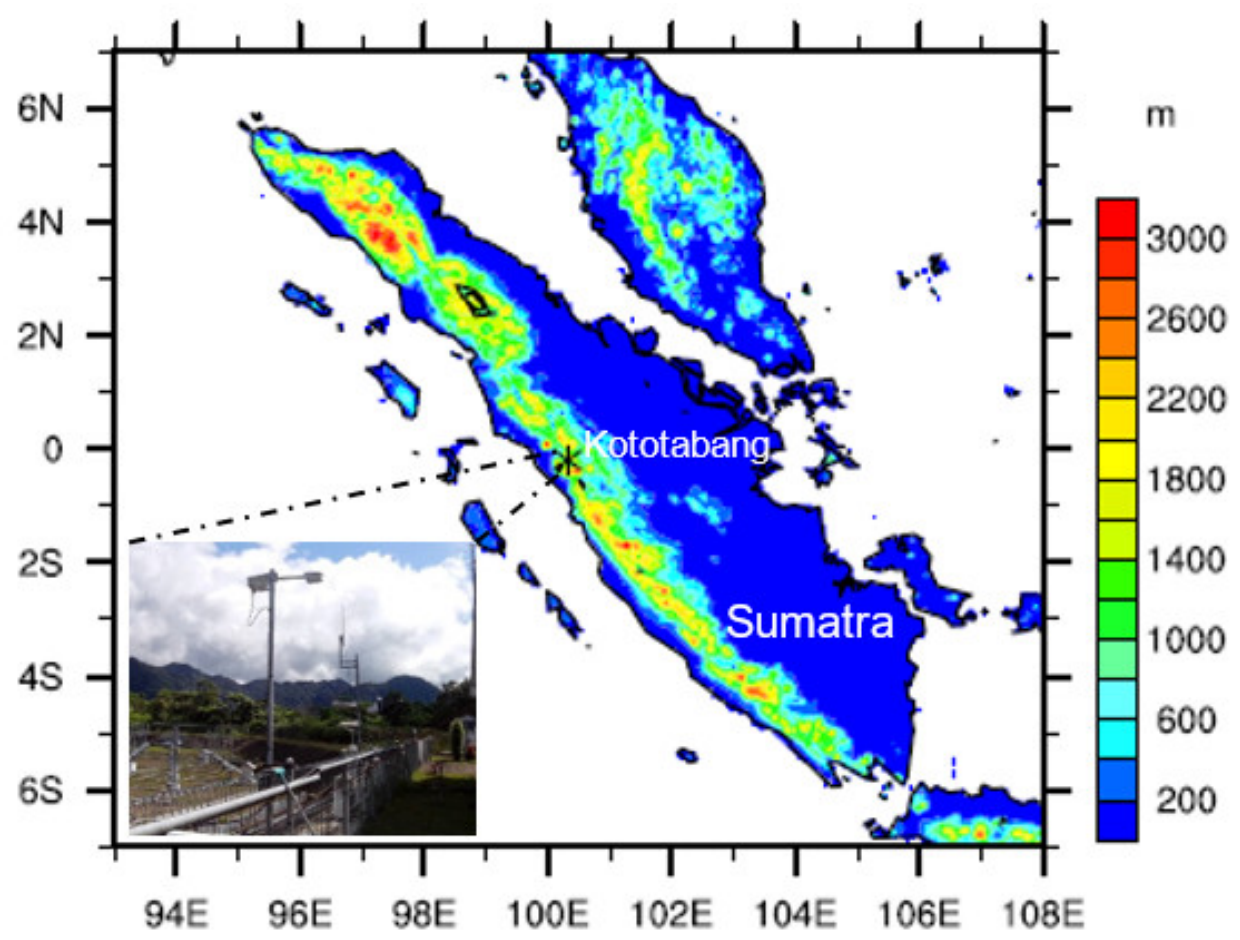

Figure 1. The topography of Sumatra and the location of the Equatorial Atmosphere Observatory (EAO) at Kototabang.

In 2001, an atmospheric observation center called the Equatorial Atmosphere Observatory (EAO) was established in Sumatra, precisely at Kototabang $\left(100.32^{\circ} \mathrm{E}, 0.20^{\circ} \mathrm{S}, 865 \mathrm{~m}\right.$ above sea level). Kototabang is located in the mountainous area of the Barisan mountains (Figure 1). The main instrument at EAO was the equatorial atmosphere radar (EAR), which was a large atmospheric radar for atmospheric observations [12]. Supporting instruments at EAO included a boundary layer radar, an X-band weather radar, a radiometer, a ceilometer, lidar, an optical rain gauge (ORG), and a disdrometer. With the use of this instrument, several research projects have been carried out, such as the Coupling Processes in the Equatorial Atmosphere (CPEA) study [13]. Although many research results have been reported using the data in the EAO, some observations have yet to be analyzed. This paper presents the results of ORG observations during 15 years of operation in Kototabang. These data are used to characterize the diurnal variation of rainfall in Kototabang, including its Madden-Julian oscillation (MJO) and seasonal signatures.

Diurnal variation is the most fundamental mode of rainfall variability in the tropics [14]. Hence, an in-depth study of the diurnal cycle in rainfall is essential in helping to understand the relationship between the rainfall processes and related factors [15]. However, studies on the diurnal cycles of rainfall remain challenging and they are often hampered by the limited observational data on an hourly scale in many parts of Indonesia, including in Sumatra. Wu et al. [8] analyzed precipitation data during March 2001 in Kototabang and demonstrated a relationship between diurnal variations and water vapor. Water vapor in Kototabang increases during the day and reaches its maximum in the late afternoon. Mori et al. [5] observed the migration of rainfall peaks in Sumatra using Tropical Rainfall Measuring Mission (TRMM) precipitation radar (PR) data for three years 
(1998-2000). They found that the rainfall peaks on mainland Sumatra were observed at 15:00 and 20:00 local standard time (LST) and were dominated by convective rain. In the early morning, stratiform and convective types of rain appeared but they were dominant in the surrounding ocean. Many other studies have investigated the diurnal variations of rainfall in Sumatra by utilizing satellite data or in situ observations over a limited period. To overcome these limitations, Marzuki et al. [11] and Suryani et al. [16] analyzed the diurnal variations of rainfall in Sumatra by analyzing rain gauge data from 186 stations throughout Sumatra, which were operated by the Meteorology, Climatology, and Geophysical Agency (BMKG). The analysis was based on rain gauge data during 2015-2019, and did not include Kototabang ORG data. These studies enriched the understanding of the rainfall in Sumatra because they examined diurnal variations from the perspectives of precipitation amount $(\mathrm{PA})$, frequency $(\mathrm{PF})$, and intensity $(\mathrm{PI})$, which have not been studied for the Sumatra area before.

This paper presents a follow-up of the work of Marzuki et al. [11], focusing on a study area in a mountainous area of Sumatra where in situ measurements remain scarce. There are several factors affecting the diurnal cycle of rainfall, namely, surface temperature, moist convection, the formation of clouds, boundary layer development [14], regional and synoptic-scale dynamical, and thermal conditions [17]. Over a mountainous area, the interaction of these factors with local-scale phenomena of land-sea and mountainvalley breezes may produce different characteristics in terms of the diurnal cycles of precipitation [8]. Marzuki et al. [18] showed the prominent role of the island's mountainous areas in the development and propagation of the precipitation system over Sumatra island.

In addition to the climatology of the diurnal cycle, the MJO and seasonal signature of the diurnal cycle in rainfall have also been investigated, and over mountainous areas these effects can be unique. Several studies have shown the effect of seasons $[19,20]$ and MJO [21] on the diurnal cycle of precipitation. MJO modulates the diurnal precipitation cycle over the Indonesian maritime continent (IMC) due to an increase in the low-level moisture background associated with MJO [21]. Furthermore, the highest amplitude of diurnal variation in precipitation was observed during the active phase of the monsoon season, as observed in the Bay of Bengal [20]. The effect of MJO and seasons is not discussed by Marzuki et al. [11] due to the limited duration of the available data. Recently, Marzuki et al. [18] investigated seasons' effects on Sumatra's diurnal cycle in relation to the land/sea contrast in precipitation, but they also did not discuss the MJO. Thus, using the 15-year data record of ORG in Kototabang will enhance our understanding of diurnal variations in Sumatra, including its MJO and seasonal signature.

The diurnal cycle of rainfall is also a critical test of many aspects of the physical parameterizations in weather and climate models [15]. Global climate models usually fail to simulate properly the regional processes and their spatial variability for precipitation in mountainous areas [22]. Hara et al. [23] compared the precipitation simulated by a 20 km-grid Meteorological Research Institute General Circulation Model (MRI-GCM) and the near-surface rain data of TRMM 2A25. They failed to simulate the diurnal cycle over islands of which the horizontal scale was larger than $200 \mathrm{~km}$, such as Sumatra and Borneo. There was a difference in peak time between MRI-GCM and TRMM 2A25 because the cumulus convective parameterization in the $20 \mathrm{~km}$ grid spacing did not adequately represent the coupling of convection and local circulations [23]. In this study, we examined the ability of the Weather Research and Forecasting (WRF) model to reproduce the diurnal cycle of the precipitation in the mountains of Sumatra, using a smaller simulation grid of $5 \mathrm{~km}$. ORG data are very useful in evaluating the ability of the WRF to capture the diurnal cycle of precipitation over a mountainous area of Sumatra. Although there are differences in the sampling area between ORG and WRF, comparisons between point rain gauges such as ORG with grid data (WRF) are widely used in the validation of precipitation from WRF models, especially with regard to diurnal cycles, for which rain gauge data are always used as a reference value. In addition to point rain gauge observations, the simulation results are also compared with gridded precipitation data from the Integrated 
Multi-satellite Retrievals for GPM (IMERG). The IMERG was chosen because these data have better temporal and spatial resolution than others [24] and are believed to be the most accurate data at present.

\section{Materials and Methods}

Precipitation data were collected on an 815 Optical Rain Gauge (ORG) during 2002-2016. ORG data in Kototabang have been used for various studies, such as telecommunication [25-27], weather radar [28], and precipitation variability studies [3,29]. This instrument was based on scintillation technology, in which raindrops fall through the beam, leading to variations in the intensity of the infrared light. These irregularities, known as scintillations, are detected by the sensor and converted to the rain rate. ORG reports the rain rate in $\mathrm{mm} \mathrm{h}^{-1}$ with the dynamic range of 0.1 to $500 \mathrm{~mm} \mathrm{~h}^{-1}$. The detailed specifications of this instrument can be found in the company website [30]. This study used a sampling time of $10 \mathrm{~min}$, which is the same as that of previous studies using rain gauge data in Sumatra [11]. In general, the availability of data was high, except for a few months (Figure 2). In 2002, the percentage of data availability was around $76 \%$ because there were no observations in January and February. In 2007, data availability was about $70 \%$ due to the absence of observations in January and February and the lack of observations in October and November $(<60 \%)$.
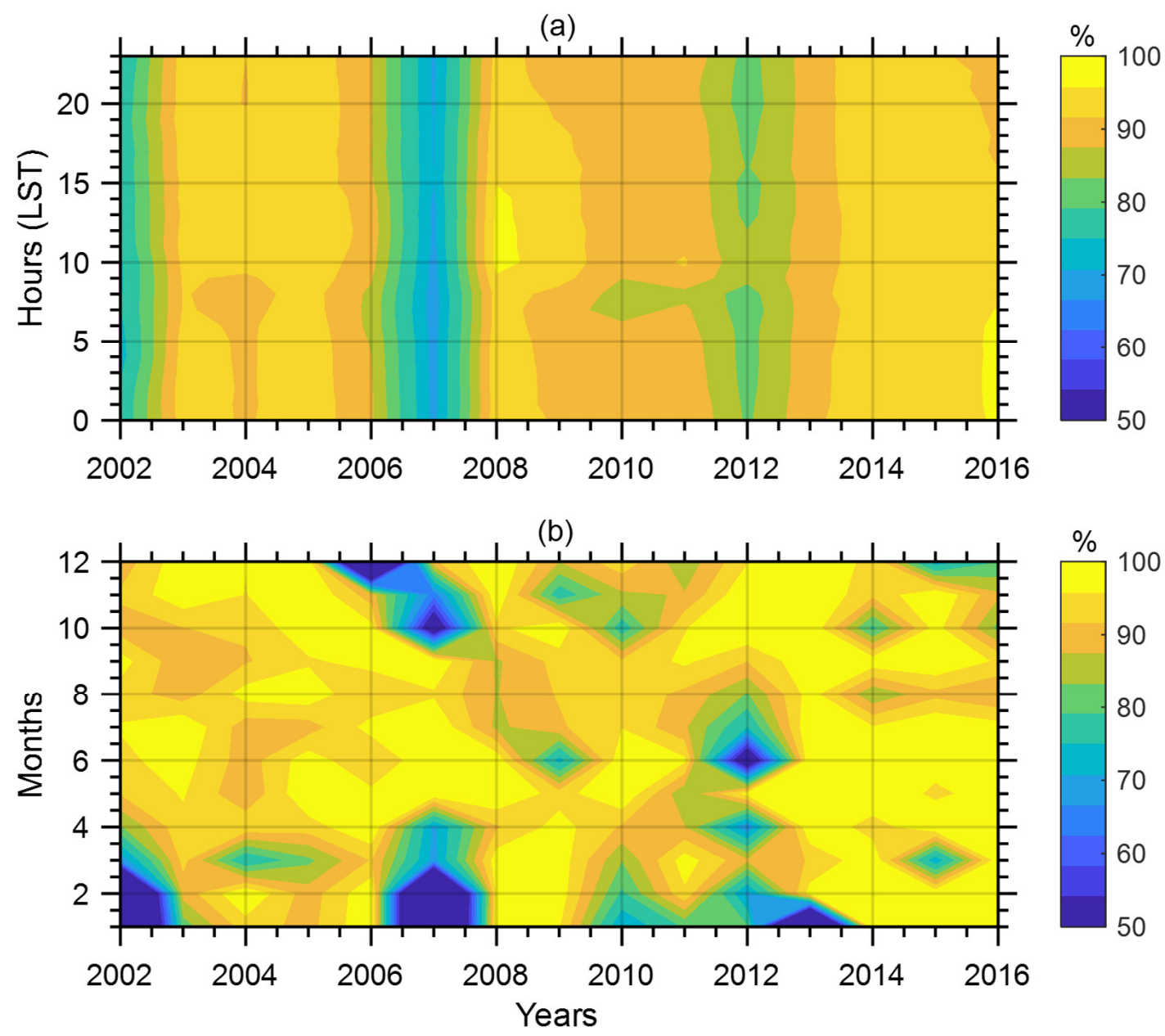

Figure 2. Availability of the data on an hourly (a) and monthly (b) basis. The percentage indicates the ratio of hourly (monthly) recorded samples to the total number of samples that would have been recorded had no measurement failures occurred during a given year.

The diurnal variation was analyzed from three parameters, namely, the precipitation amount (PA), precipitation frequency $(\mathrm{PF})$, and precipitation intensity (PI). PA is defined as 
the total accumulated rainfall divided by the total hours of observation. Furthermore, the PF is the total 10-min data with rain above $0.1 \mathrm{~mm} \mathrm{~h}^{-1}$ divided by the total $10-\mathrm{min}$ observation data, and PI is defined as the total accumulated rainfall divided by the number of rainy hours $\left(R \geq 0.1 \mathrm{~mm} \mathrm{~h}^{-1}\right)$. The definitions of PA, PF, and PI, are the same as those presented in the previous study [11]. Calculations were carried out for each hour in local standard time (LST) units. The precipitation at Kototabang is influenced by seasons and MaddenJulian oscillation (MJO) [3,31-34]. Therefore, the effect of seasons on the diurnal variation of rainfall was investigated by calculating PA, PF, and PI for each month. In addition, the effect of the MJO on the diurnal variation of rainfall in Kototabang was also investigated. The MJO index was downloaded from the Australian Meteorological Agency website [35]. This study only considered strong MJO, which is indicated by an MJO index more than one. The effect of MJO was observed for the period of December-January-February (DJF), March-April-May (MAM), June-July-August (JJA), and September-October-November (SON), which was based on the convection pattern in the IMC $[2,34,36]$. The duration of a rain event can also affect the peak time of the rain [37]. To investigate such an effect, we classified rain events into three durations, following Marzuki et al. [11], namely, $<3 \mathrm{~h}$ (short-duration rain events), 3-6 h (medium-duration rain events), and $>6 \mathrm{~h}$ (long-duration rain events), as also used by Marzuki et al. [11]. A rain event was defined as a continuous event that was not interrupted by an hourly rainfall of less than $0.1 \mathrm{~mm}$.

The diurnal variations of precipitation from the ORG data were compared with satellite-derived (Integrated Multi-satellite Retrievals for the Global Precipitation Measurement (GPM) mission (IMERG)) and atmospheric model outputs (WRF, Weather Research and Forecasting). IMERG data were available in $0.1^{\circ}$ grids every half hour. The IMERG precipitation product is generated from the GPM mission, which unifies observations from a network of partner satellites in the GPM constellation [38]. In this study, IMERG final-run product V06 (IMERG-F) was used, since it is recommended for research activities due to its better accuracy ([39]. The WRF simulations were carried out with a nest domain with a horizontal resolution of $25 \mathrm{~km}$ in the outer domain and $5 \mathrm{~km}$ in the inner domain (Figure 3). The model was configured with 32 vertical layers with $50 \mathrm{hPa}$ at the top level. The WRF model was setup in a non-hydrostatic mode and was initialized and forced with the European Centre for medium-range weather forecasting (ECMWF) reanalysis (ERA-Interim). The time scale for this experiment was 3 years of simulation with a 1 year spin-up time from 2013 to 2017. The physics options for this experiment followed those of Ratna et al. [40]. These included the WSM 3-class simple ice scheme for microphysics schemes [41], the Unified NOAH scheme for land surface schemes [42] and Betts-Miller-Janjic scheme for cumulus analysis $[43,44]$. Short-wave and long-wave schemes were based on the Dudhia scheme and the Yonsei University model (RRTM) scheme, respectively $[45,46]$.

The difference in sampling area between ORG point observations and IMERG-based and WRF-based grid values can cause uncertainty when these three forms of data are directly compared. To quantitatively evaluate the performance of WRF and IMERG-F in estimating hourly rainfall at Kototabang, several statistical parameters were calculated as in Table 1. The equation to calculate these parameters can be seen in some references, e.g., [47]. The observation accuracy of IMERG-F and WRF data is still low compared to that of ORG, as can be seen from the low CC and high RMSE and RB values. The RB values of IMERG and WRF, when compared with ORG, are positive. WRF has the largest RB value when compared to ORG. Although the accuracy of IMERG and WRF is still not good when observing hourly rainfall, the ability of IMERG data and the WRF model to detect hourly rainfall is good enough, as can be seen from the POD value. Although the POD value is good enough, IMERG and WRF were often wrong in detecting hourly rainfall in Kototabang, as seen from the high FAR value. This result may indicate the inability of one observation point to represent rainfall variations in one WRF grid $(5 \mathrm{~km} \times 5 \mathrm{~km})$ and IMERG-F grid $\left(0.1^{\circ} \times 0.1^{\circ}\right)$ due to significant small-scale spatial rainfall variability in the mountainous area of Sumatra. However, the comparison between WRF and IMERG, which are grids of data, does not produce better results even though the POD value between ORG 
and IMERG is better than that between IMERG and WRF (Table 1). The test results show that the POD values of the three data are good enough, which indicates their potential to detect the same rain. In addition, a time series of hourly IMERG-F data shows that IMERG-F can capture the temporal trends of hourly precipitation, in comparison with point rain gauge observations [48,49]. Therefore, although caution is needed, the comparison of these three data will provide valuable information regarding the performance of each data in describing the diurnal cycle of precipitation.

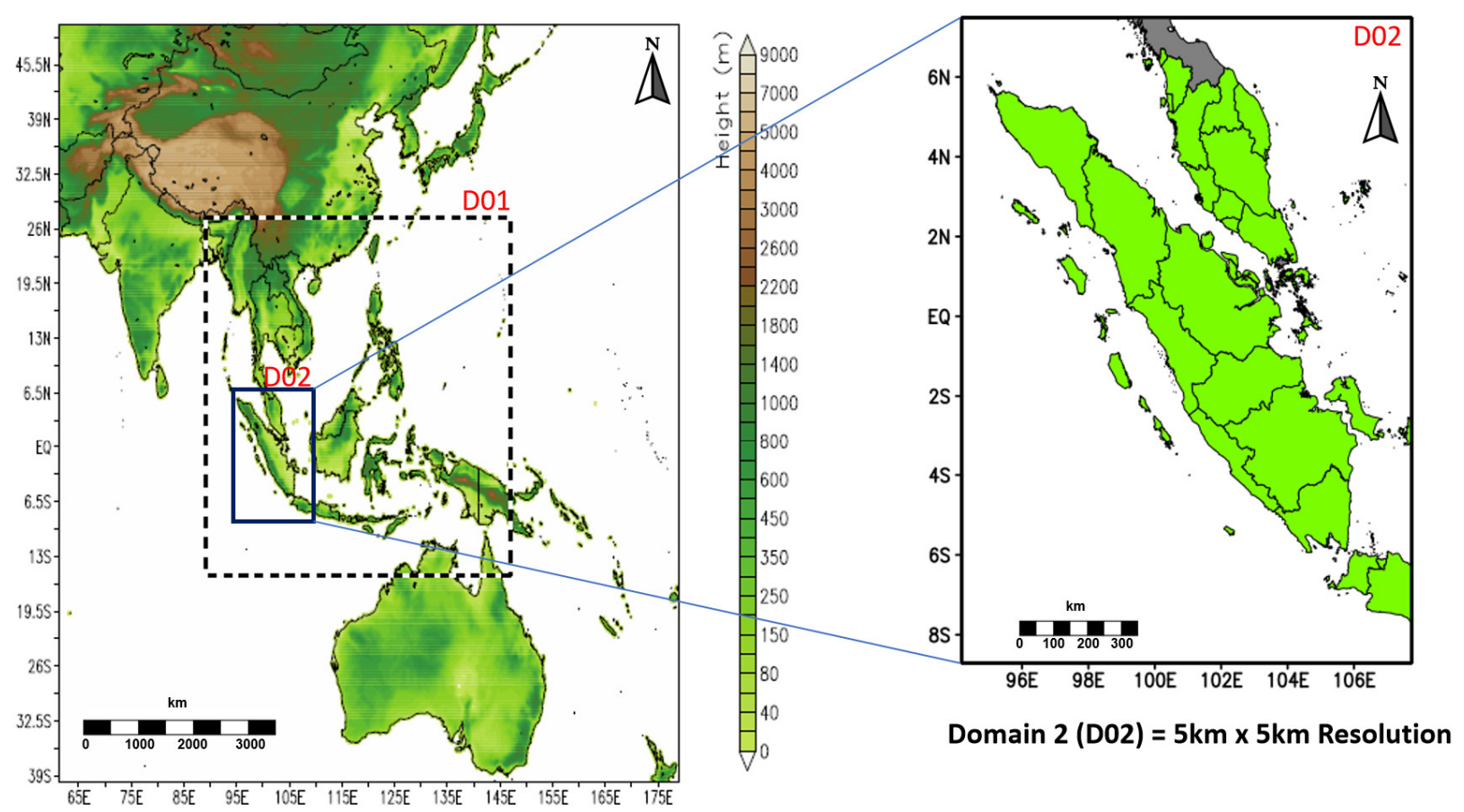

Domain $1(D 01)=25 \mathrm{~km} \times 25 \mathrm{~km}$ Resolution

Figure 3. Spatial configuration of the domains used in the WRF simulations.

Table 1. Evaluation metrics calculated for ORG, WRF, and IMERG-F data at Kototabang for two rainfall rate $(R)$ thresholds.

\begin{tabular}{cccc}
\hline Parameters & ORG-WRF & IMERG-WRF & ORG-IMERG \\
\hline $\begin{array}{c}\text { Threshold: } R \geq 0.1 \\
\text { Correlation coefficient (CC) }\end{array}$ & 0.091 & 0.125 & 0.286 \\
\hline Root-mean-square error (RMSE) & 5.255 & 2.807 & 3.678 \\
\hline Relative bias (RB) & 0.313 & 0.179 & 0.123 \\
\hline Probability of detection (POD) & 0.480 & 0.418 & 0.767 \\
\hline False alarm ratio (FAR) & 0.799 & 0.554 & 0.698 \\
\hline Critical success index (CSI) & 0.165 & 0.275 & 0.279 \\
\hline Threshold: $R \geq 0.5$ & 0.088 & 0.117 & 3.713 \\
\hline Correlation coefficient (CC) & 2.853 & 0.046 \\
\hline Root-mean-square error (RMSE) & 0.225 & 0.642 \\
\hline Relative bias (RB) & 5.284 & 0.336 & 0.701 \\
\hline Probability of detection (POD) & 0.270 & 0.699 & 0.256 \\
\hline False alarm ratio (FAR) & 0.394 & 0.189 & \\
\hline Critical success index (CSI) & 0.835 & 0.132 & \\
\hline
\end{tabular}




\section{Results and Discussion}

\subsection{Climatology of Diurnal Cycles of PA, PF, and PI}

Figure 4 shows the diurnal variations in PA, PF, and PI from the ORG observation in Kototabang during 2002-2016. The average climatological PA, PF, and PI were $0.26 \mathrm{~mm} \mathrm{~h}^{-1}$, $7.40 \%$, and $3.16 \mathrm{mmh}^{-1}$, respectively, which are similar to those obtained from rain gauge data in Sumatra, as described in Marzuki et al. [11], especially for PA. About $98 \%$ of the rain gauge stations operated by the Meteorology, Climatology, and Geophysical Agency (BMKG) showed an average PA value of $<0.5 \mathrm{~mm} \mathrm{~h}^{-1}$ [11]. Both PA, PF, and PI showed a single peak, in contrast to those found in the UK, which show two peaks [15]. Rain is more frequent in the late afternoon, which is indicated by a larger PF, but the intensity (PI) is larger in the early afternoon. The peak time of PI was observed at 13:00-14:00 LST with a peak value of $6.55 \mathrm{~mm} \mathrm{~h}^{-1}$. On the other hand, peaks of PF and PA were observed at 17:00 LST, with values of $13.3 \%$ and $0.68 \mathrm{~mm} \mathrm{~h}^{-1}$, respectively. The diurnal peak exhibited high $\mathrm{PI} /$ low PF, suggesting that both PI and PF are important indicators of PA, as is found in the Philippines [50]. However, the contribution of PF to PA is much greater than that of PI because the peak time of PA is always similar to that of PF (Figure 4).

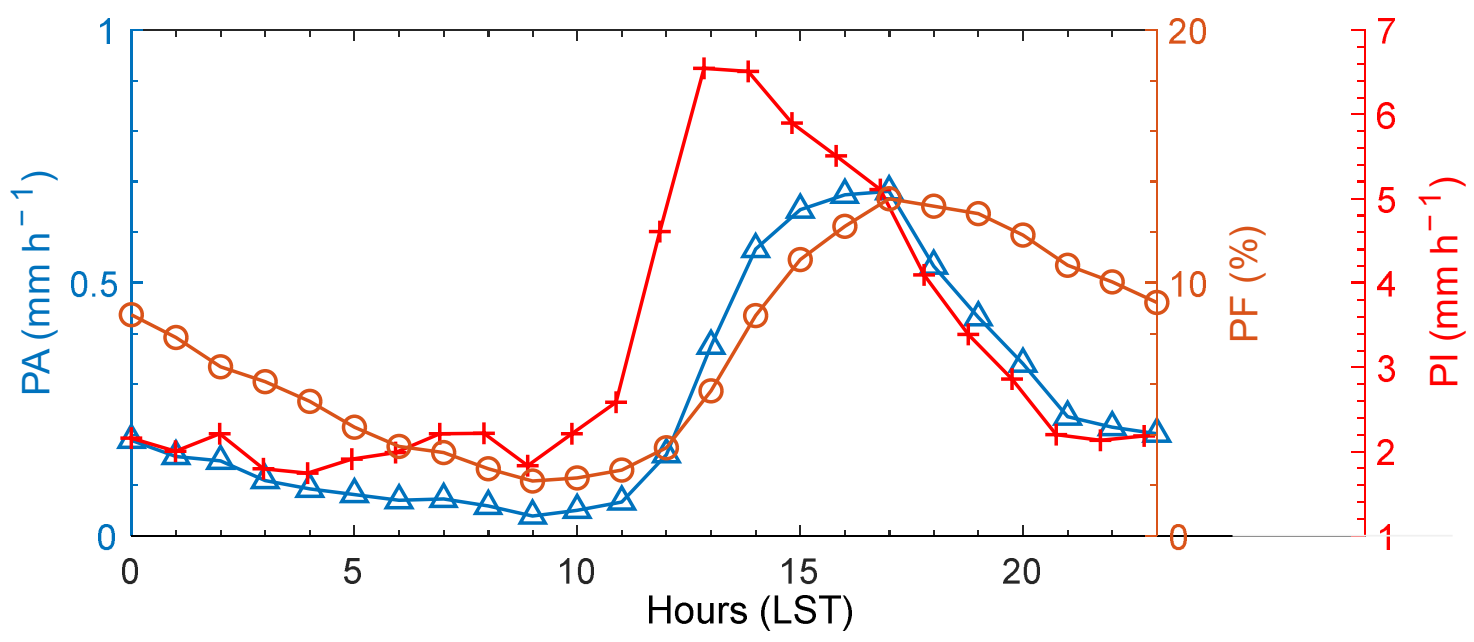

Figure 4. Climatology of diurnal variations of PA (blue), PF (merigold), and PI (red) at Kototabang during 2002-2016.

\subsection{Diurnal Cycles of PA, PF, and PI with Different Durations}

Rain in Kototabang is dominated by short-duration rain events $(<3 \mathrm{~h})$. During 2002-2016, 3996 rain events were observed, in which 3089 events $(77.3 \%)$ were shortduration rain events. Furthermore, $670(16.8 \%)$ and $237(5.9 \%)$ were rain events of $3-6 \mathrm{~h}$ and $>6 \mathrm{~h}$ in duration. Previous studies in Sumatra that were based on the BMKG rain gauge and IMERG observation data also showed the dominance of short-duration rain events, with percentages of $50-80 \%$ [18].

Figure 5 shows the diurnal variations in PA, PF, and PI for events with different durations. The peak time of short-duration rain events came earlier than that of longduration events. For PA, rain peaks were observed at 14:00, 17:00, and 17:00 LST for $<3 \mathrm{~h}$, 3-6 h, and $>6 \mathrm{~h}$ rain event durations, respectively. Moreover, for PF, peaks were observed at 15:00, 18:00, and 22:00 LST. Significant differences in peak time were not observed for PI, where, for events with durations $<3 \mathrm{~h}$, peaks were observed at 13:00-14:00 LST, whereas peaks for events with durations $>6 \mathrm{~h}$ were observed at 15:00 LST. The dependence of the rain peak on the duration of the rain, as observed in this study, is consistent with previous studies in Sumatra [18]. 
(a)

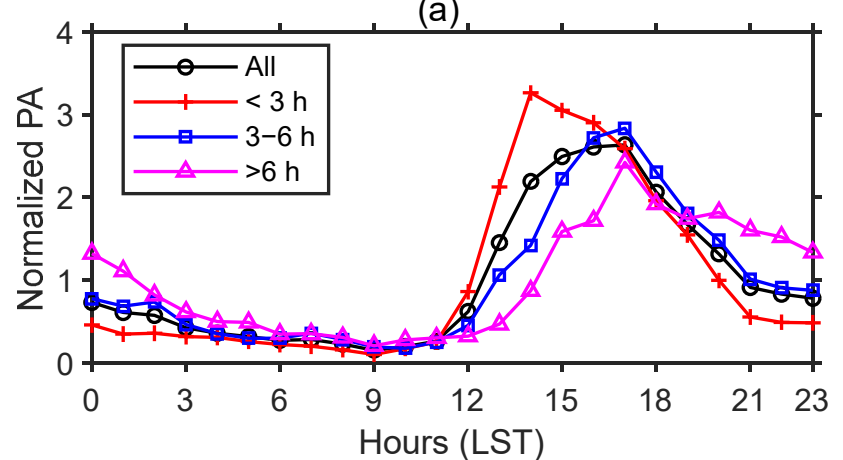

(b)
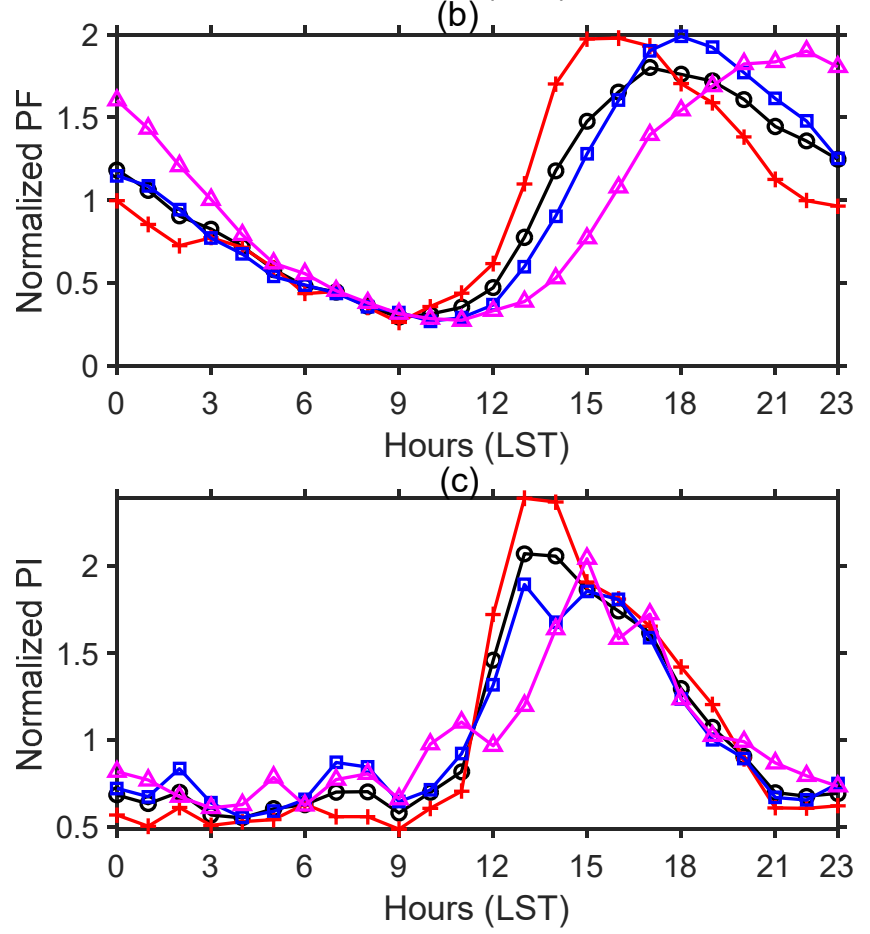

Figure 5. Diurnal variations in PA (a), PF (b), and PI (c) for different rain event durations. PA, PF, and PI values for each hour were divided by the average value.

The difference in rainfall peaks for each duration is consistent with the evolution of MCS clouds. Based on radar observations at Kototabang, short durations of heavy convective rain are often followed by longer durations of light rain from the stratiform portion of the cloud system [7]. The occurrence ratio between stratiform and deep convective rain is about 3:2, which contributes to the $2: 3$ ratio of total rainfall $[7,29]$. This ratio is comparable to that found in this study. The stratiform peak (long-duration rain) comes later than convective precipitation (short-duration rain), which is consistent with Figure 5.

\subsection{Seasonal Changes in Diurnal Cycles of PA, PF, and PI}

Figure 6 shows the PA, PF, and PI values for each month. PA and PF values in April and November were larger than those in other months. The highest PA value was observed in April at 15:00 LST with a value of $1.08 \mathrm{~mm} \mathrm{~h}^{-1}$, followed by November with a PA of $1.00 \mathrm{~mm} \mathrm{~h}^{-1}$ at 16:00 LST. The minimum PA value was observed in July with a value of $0.50 \mathrm{~mm} \mathrm{~h}^{-1}$ at 15:00 LST. For PF, the highest value was observed in November with $21.7 \%$ at 22:00 LST, followed by April with $18.42 \%$ at 17:00 LST. Similarly to PA, the minimum value of PF was also observed in July, with a value of $8.66 \%$ at 17:00 LST. On the other hand, for PI, the highest value was observed in February with $9.73 \mathrm{~mm} \mathrm{~h}^{-1}$ at 13:00 LST, followed by August with a value of $9.62 \mathrm{~mm} \mathrm{~h}^{-1}$ at 13:00 LST. The two peaks of PA and $\mathrm{PF}$ found in this study were consistent with the monsoon season. In terms of season, the 
Kototabang area can be divided into four seasons; pre-southwest (April-May), southwest (June-September), pre-northeast (October-November), and northeast (December-March). Pre-southwest and pre-northeast monsoons are wet seasons at Kototabang [34]. The two peaks of PA and PF were also associated with the southward and northward movement of the inter-tropical convergence zone (ITCZ) [51]. Consistently with a previous study [36], the peaks of PA and PF in November were much higher than those in April.
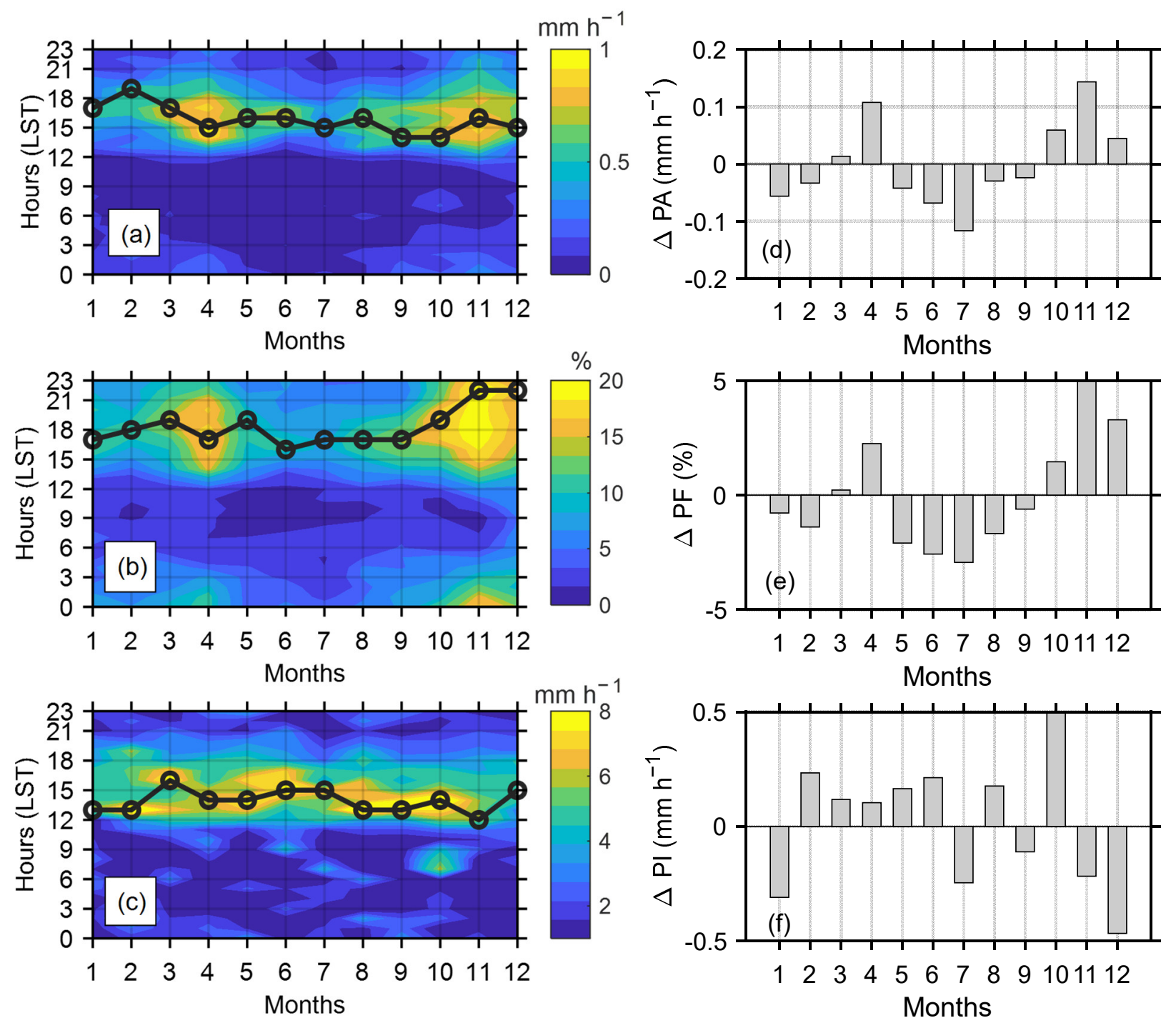

Figure 6. Monthly variations in diurnal cycles of PA (a), PF (b), and PI (c), as well as their differences $(\Delta)$ with average climatological values $(\mathbf{d}-\mathbf{f})$ described in Section 3.1. Lines with circle markers indicate the peak times of PA (a), PF (b), and PI (c).

The minimum PI was observed in the month when the PA and PF values were at the maximum. Thus, PA was more influenced by PF than PI, as also observed in Figure 4 . This condition can be seen more clearly in the differences $(\Delta)$ of PA, PF, and PI values with the averages of the climatological values as described in Section 3.1. In general, when $\triangle \mathrm{PA}$ and $\triangle \mathrm{PF}$ are positive, the value of $\Delta \mathrm{PI}$ is negative (Figure $6 \mathrm{~d}-\mathrm{f}$ ).

The number of rain events also showed monthly variations, with the highest number in April and November (Figure 7). During April, 369 short-duration rain events $(<3 \mathrm{~h})$ were observed, accounting for $79 \%$ of the total events. Furthermore, 346 (70\%) short-duration rain events were observed during November. In June and July, the number of rain events was much smaller than in April and November, but the percentages of short-duration 
rain events were higher, namely, $84 \%$ and $82 \%$, respectively. The lack of medium- and long-duration run events during this period caused small PA and PF values (Figure 6d,e). The increase in the number of medium- and long-duration rain events during April and November is partially due to the favorable environmental shear conditions necessary to sustain a long-lived cloud system [2]. Seasonal variations in long-duration rainfall events had also been observed in central-eastern China [52].
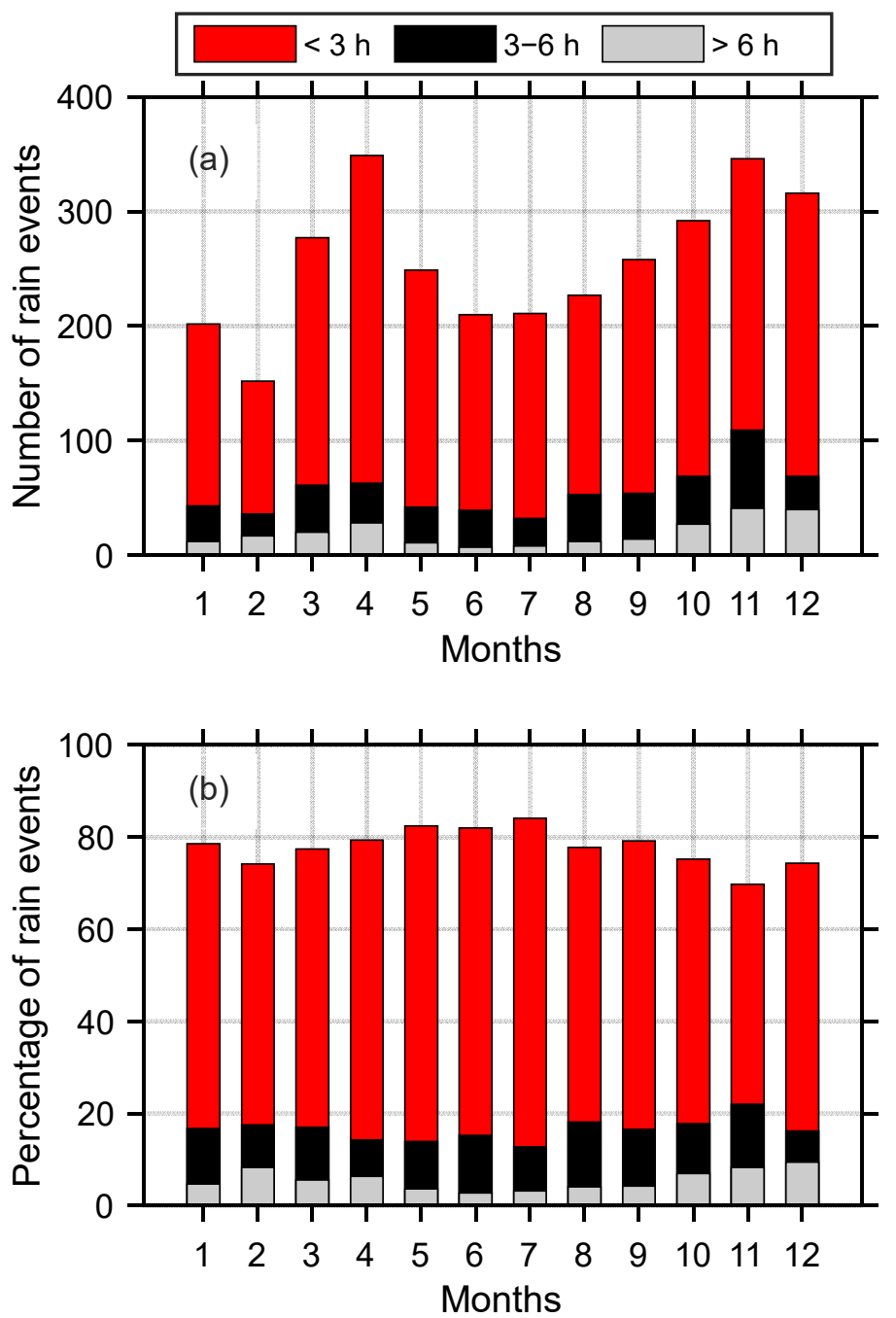

Figure 7. Monthly variations in the number $(\mathbf{a})$ and percentage $(\mathbf{b})$ of rain events for different rain event durations. The percentages shown in Figure $7 \mathrm{~b}$ were calculated by dividing the number of events for each duration by the total number of events in that month.

Although there was an increase in PA and PF (Figure 6a,b), as well as the number of rain events (Figure 7) during the pre-southwest (April-May) and pre-northeast (OctoberNovember), the peak times for PA and PF did not shift significantly. PA and PF with high values were observed longer (15:00-03:00 LST the next day) (Figure 6a,b), but later peak times were only evident for PF during the pre-northeast monsoon, which is consistent with the BMKG rain gauge observations [18].

\subsection{Effect of MJO on Diurnal Cycles of PA, PF, and PI}

Figure 8 shows the effect of the MJO on the diurnal variation of precipitation in Kototabang. There was an increase in PA and PF values in phases 2, 3, and 4, with the maximum values observed in phase 3 , namely, $1.21 \mathrm{~mm} \mathrm{~h}^{-1}$ and $21.39 \%$, respectively. A smaller PA value was observed in phases 5 to 7 , around $0.33,0.49$, and $0.40 \mathrm{~mm} \mathrm{~h}^{-1}$. Such 
a condition was also observed for PF, with values for phases 5, 6, and 7 being $8.91 \%, 7.10 \%$, and $7.48 \%$. The average PA and PF values during phases 2, 3, and 4 were larger than the average climatological PA and PF values in Kototabang. In contrast, the average values in phases 5, 6, and 7 were smaller than the climatological values (Figure 8d,e). Although the highest PA and PF values were observed in phase 3, the PI value was relatively small in this phase $\left(\sim 7.15 \mathrm{~mm} \mathrm{~h}^{-1}\right)$, smaller than the climatological PA value in Kototabang (Figure 7f). During the active phase of the MJO (phases 2-4), cloud clusters (CCs), which developed in the convective envelope of a super cloud cluster (SCC) with a period of several days, mainly induced the formation of convective activities over Sumatera $[3,33,53]$. On the other hand, during the inactive phase of $\mathrm{MJO}(5-8)$, convective activities caused by local circulation were prominent at Kototabang [53].

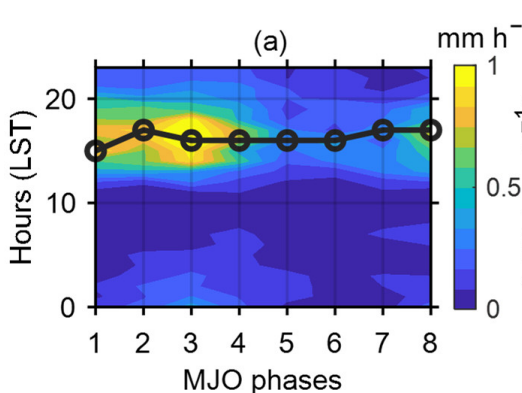

(b)

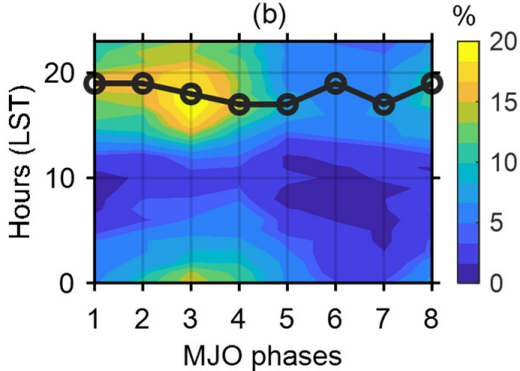

(c)

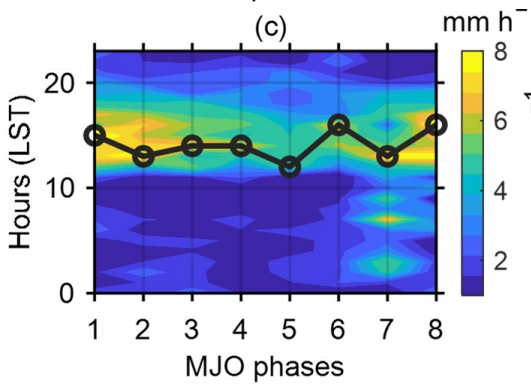

(d)

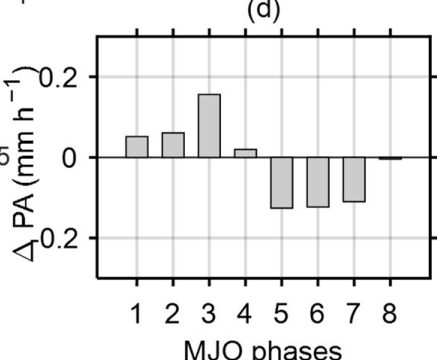

(e)

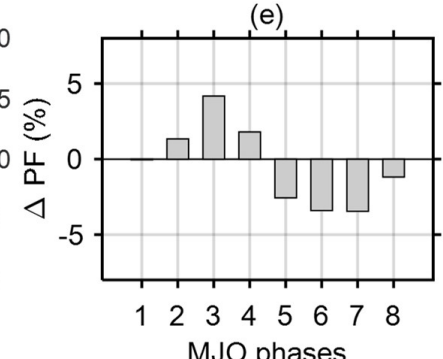

(f)

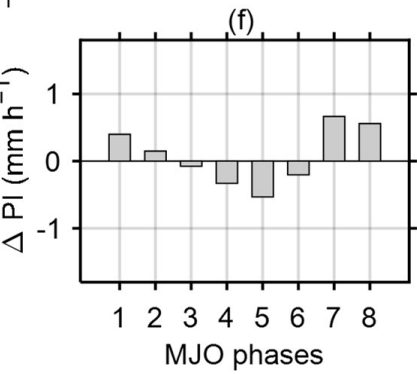

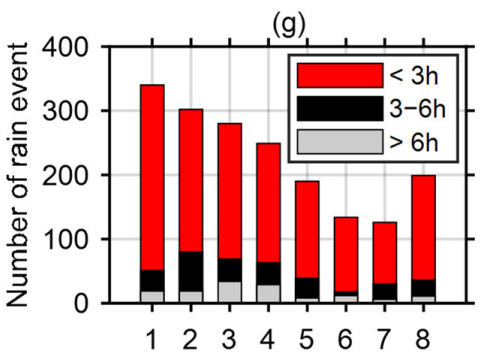
MJO phases

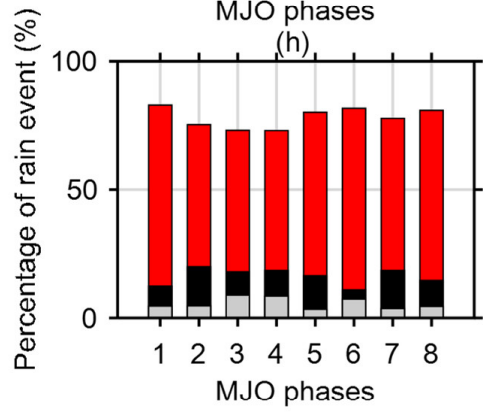

Figure 8. Intraseasonal variations in terms of MJO of the diurnal cycle of PA (a), PF (b), and PI (c), as well as their differences $(\mathbf{d}-\mathbf{f})$ with the average climatological values described in Section 3.1, along with the number $(\mathbf{g})$ and percentage $(\mathbf{h})$ of rain events for different rain event durations. Lines with circle markers indicate the peak time of PA (a), PF (b), and PI (c). The percentage shown in Figure 8h is calculated by dividing the number of events for each duration by the total number of events in that MJO phase.

The number of rain events in Kototabang was highest in phase 1 and decreased as the MJO phase increased (Figure $8 \mathrm{~g}$ ). The number of rain events increased again in phase 8 . Although the number of rain events was huge in phase 1, rain in this phase was dominated by short-duration rain events $(83 \%)$, followed by medium-duration rain events $(12.44 \%)$ and long-duration rain $(4.63 \%)$. The number of medium- and long-duration rain events increased in phases 2, 3, and 4, along with the increase in the convective system induced by CCs over Sumatra $[3,33,53]$. The percentage of short-duration rain events $(<3 \mathrm{~h})$ during phases 2,3 , and 4 were $75.31 \%, 73.11 \%, 73.02 \%$, respectively. Furthermore, the percentage of rain events with durations from $3-6$ h were $19.95 \%, 18.02 \%$, and $18.48 \%$. For rain events 
with durations $>6 \mathrm{~h}$, the values were $4.74 \%, 8.88 \%$, and $8.50 \%$, respectively (Figure $8 \mathrm{~h}$ ). This feature is consistent with Figure 8b, where relatively high PF values in phases 2, 3 and 4, were observed from 12:00 LST to 5:00 LST (the next day), indicating a relatively high number of medium- and long-duration rain events. On an annual basis, MJO phases 1 occurred more often than the other phases throughout the year [54], so the number of rain events in this phase was also greater (Figure $8 \mathrm{~g}$ ).

The peak times of PA and PF were slightly different for each MJO phase. The PA peak in phase 2 was 17:00 LST, whereas for phases 3-6 the peak was 16:00 LST. In phases 7 and 8, the peak was 17:00 LST (Figure 8a). The peak time of PF varied between 17:00 and 19:00 LST. During phases 2, 3, and 4, PF peaks were observed at 19:00, 18:00, and 17:00 LST, respectively (Figure 7b). The PI peaks fluctuated more and peaks were observed at 13:00, 14:00, and 14:00 LST during phases 2, 3, and 4. During phase 8, the peak time of PI was observed at 16:00 LST (Figure 8c). Thus, the diurnal cycle of precipitation at Kototabang increased during the active MJO (phases 2-4) compared with the suppressed MJO (phases $5-8)$, but the diurnal phase was similar in both regimes, which was consistent with some previous studies $[21,55]$.

Figure 9 shows the effect of MJO on PA, PF, and PI on a seasonal basis. Due to the limited number of rain events for each month, the result is displayed for the DJF, MAM, JJA, and SON periods. In general, the effect of MJO for each season was similar, with the PA and PF values during phases 1-4 being larger than phases 5-8. Furthermore, the PA and $\mathrm{PF}$ values during phases 1-4 were larger than the average climatological PA, in contrast to phases $5-8$, in which the values were smaller than the climatological values. Slightly different conditions were observed during JJA, where, in general, PA and PF were negative, indicating a suppressed convection period (Figure 9g,h). During JJA, the number of strong MJO events (index $\geq 1$ ) was much smaller than in other periods [54].
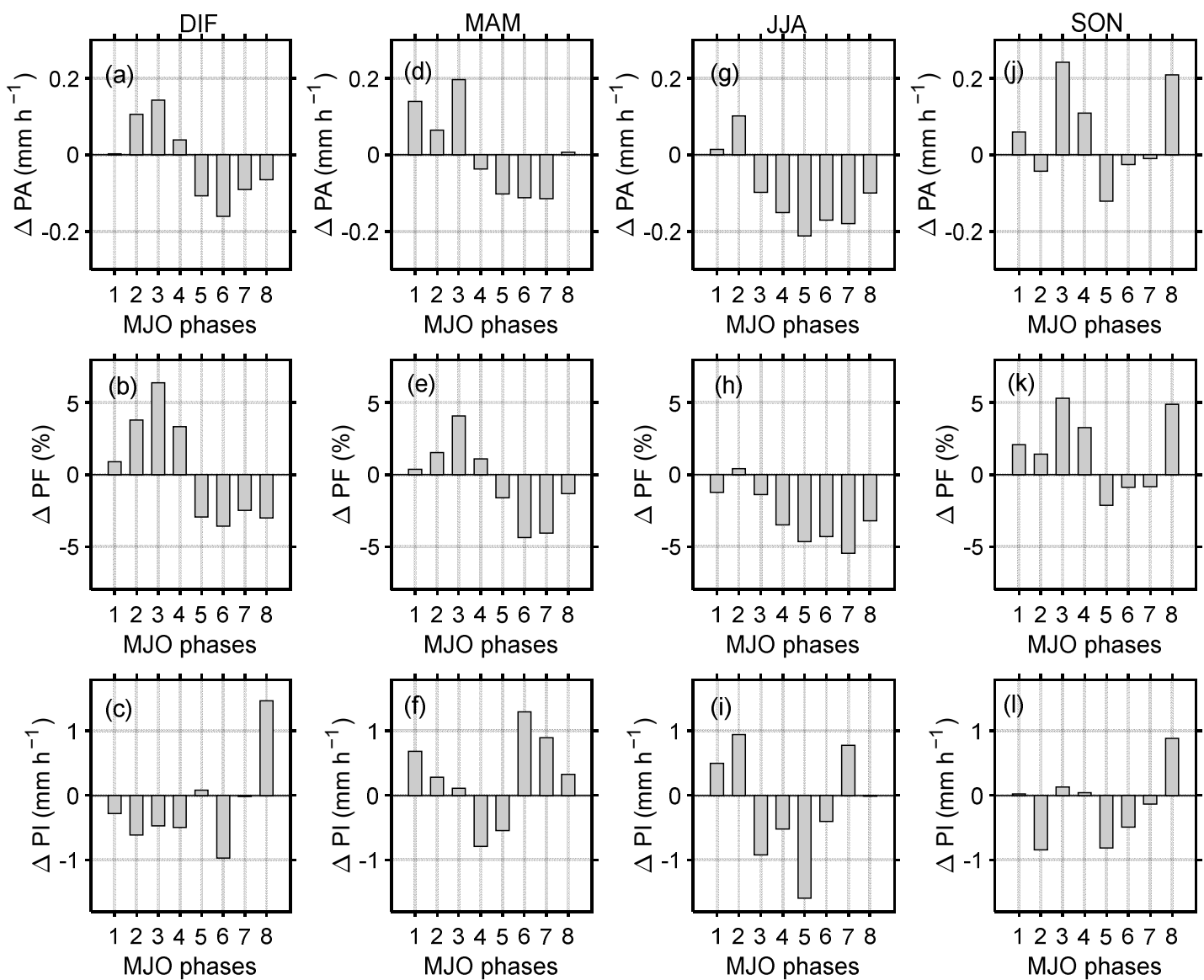

Figure 9. Same as Figure 7(d-f), but for DJF (a-c), MAM (d-f), JJA (g-i), and SON (j-1) periods. 


\subsection{Comparison of Diurnal Cycle from ORG with IMERG and WRF Model}

Figure 10 shows the comparison of the diurnal cycle from the ORG data with the WRF model IMERG-F data. Since the WRF simulations were carried out only for the period of 2013-2015, the comparison to the ORG and IMERG-F data was carried out only for this limited period. The results of the WRF model were averaged for the grids of $100.2965-100.3417^{\circ} \mathrm{E}$ and $-0.2304-0.1851^{\circ} \mathrm{S}$, whereas the IMERG-F data were taken from the closest grids to Kototabang $\left(-0.25^{\circ} \mathrm{S}\right.$ and $\left.100.35^{\circ} \mathrm{E}\right)$. The WRF model produced the same diurnal cycle phase as the ORG data. Both PA and PF peaks were observed at 16:00 LST (Figure 10a,b,d,e). The PA and PF peaks of IMERG-F were observed at 18:00 LST, which differed by two hours from those of ORG and WRF. Such differences have also been found in Sumatra using BMKG rain gauge data [18] and in China [49]. The PI values of both the WRF and IMERG-F models did not show a significant diurnal pattern, in contrast to the ORG data, which showed dominant peaks at 14:00 (Figure 10c) and at 14:00-16:00 LST (Figure 10f).
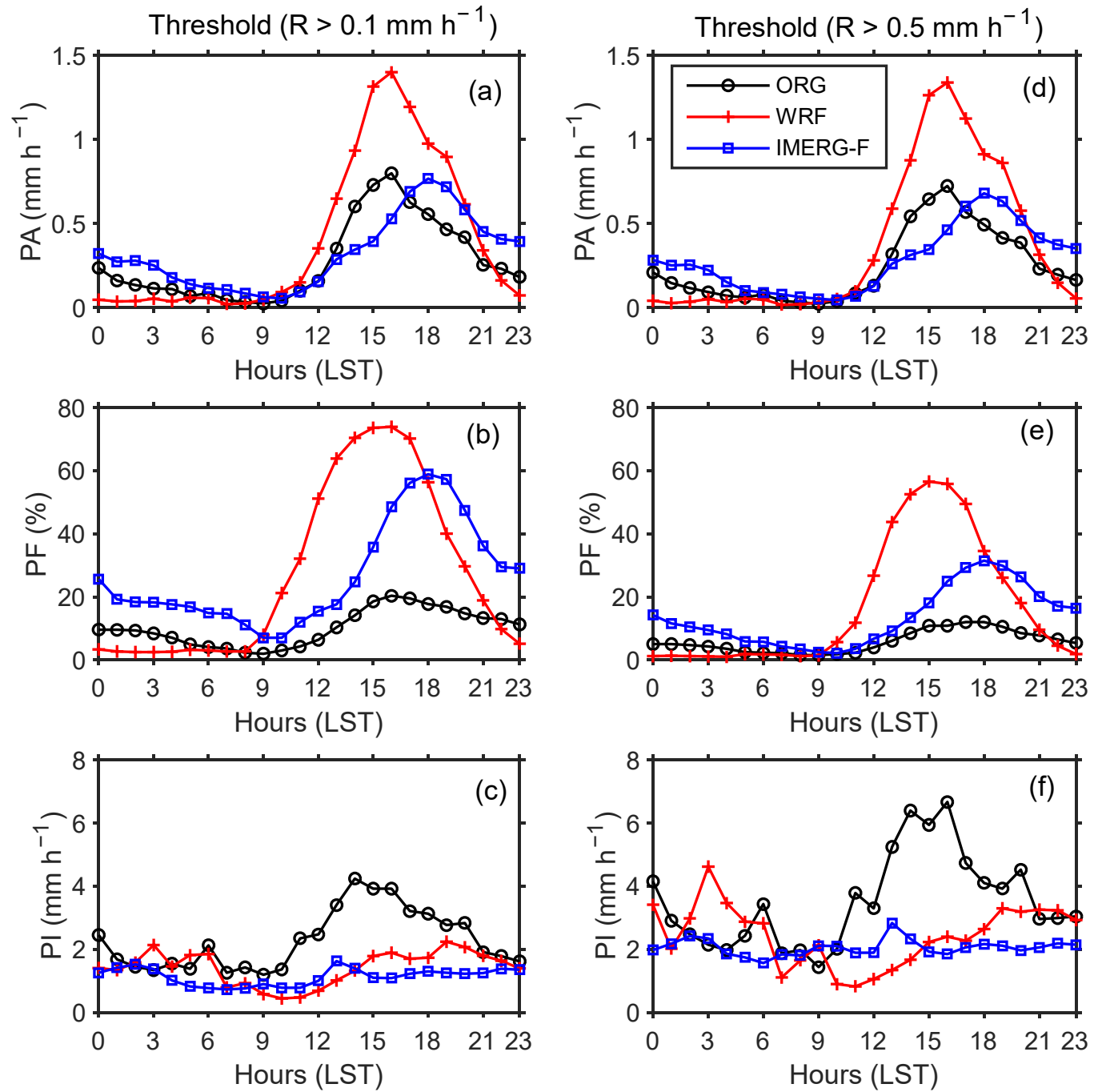

Figure 10. Comparison of diurnal variation of PA, PF, and PI from ORG with the WRF model and IMER-F data during 2013-2015. Calculations used two rainfall rate $(R)$ thresholds: $R>0.1 \mathrm{~mm} \mathrm{~h}^{-1}(\mathbf{a}-\mathbf{c})$ and $R>0.5 \mathrm{~mm} \mathrm{~h}^{-1}(\mathbf{d}-\mathbf{f})$.

Although the phase of the diurnal cycle in the WRF and ORG data is the same, the amplitudes of the two are different. The PA and PF peaks of the WRF model are much larger than those of the ORG. The peaks of PA (PF) of the ORG, WRF, and IMERG data for a threshold $R>0.1 \mathrm{~mm} \mathrm{~h}^{-1}$ were 0.80 (20.36), $1.40(73.92)$, and $0.77 \mathrm{~mm} \mathrm{~h}^{-1}(58.92 \%)$, 
respectively. The PF amplitude from the WRF model is three times larger than that of the ORG. The PA peak of ORG was close to the PA peak of IMERG. WRF's success in modeling diurnal cycle phases, as well as its failure to represent precipitation frequency and intensity, for mountainous areas have also been reported in Peru [22].

The significant difference between the diurnal cycle amplitude between WRF and ORG may be caused by several reasons. First, it may have come from a high FAR value. Although the POD value was good enough, WRF was often wrong in detecting hourly rainfall in Kototabang, as seen from the high FAR value (Table 1). This may also be the cause for the high PF value. Second, the high value of FAR may be caused by the inability of one observation point to represent rainfall variations in one WRF grid $(5 \mathrm{~km} \times 5 \mathrm{~km})$ due to significant small-scale spatial rainfall variability in the mountainous area of Sumatra. However, WRF had a better resolution than the IMERG-F grid $\left(0.1^{\circ} \times 0.1^{\circ}\right)$, but the POD value from ORG vs. IMERG was better than IMERG vs. WRF (Table 1). Even the peak PA values between ORG and IMERG-F were almost the same. Thus, this difference is not solely due to the difference in sampling area between ORG and WRF but is also influenced by the performance of WRF in modeling diurnal cycles in mountainous areas.

\section{Conclusions}

The diurnal precipitation cycle at Kototabang presented a single peak in the late afternoon, and the peak time was closely related to the duration of rain events. The peak time of short-duration rain events came earlier than those of medium- and long-duration events, which is consistent with the evolution of the mesoscale convective system (MCS). $\mathrm{MJO}$ and the seasons influence the diurnal cycle of precipitation at Kototabang. This influence is more dominant on the diurnal amplitude than the diurnal phase. The mean and diurnal maximum values of precipitation amount $(\mathrm{PA})$ and frequency $(\mathrm{PF})$ increased significantly during the active MJO stage (phases 2-4) compared with the suppressed MJO stage (phases 5-8). Increases in PA and PF were also observed during the pre-southwest and pre-northeast monsoons. In addition to PA and PF, the number of medium- and longduration rain events also increased. However, the phase of the diurnal cycle was similar in all MJO phases and seasons, indicating the dominant late afternoon peak of rainfall events from convective activities caused by local circulation. WRF simulation reproduced the phases of the diurnal cycle correctly, but it largely overestimated the amplitude of the diurnal cycle compared to ORG. A complex interaction between local circulation and other factors in mountainous areas may be the cause of this shortcoming. MJO and seasons may modify the local circulation at Kototabang. This issue is being investigated, and the results will be published in another journal. In addition, the WRF model testing in this study was still limited to one point of observation. More extensive testing using more rain gauge stations will also need to be carried out in the future.

Author Contributions: Conceptualization, M.M.; methodology, M.M.; software, H.Y., R.R. and A.A.B.A.; formal analysis, M.M.; investigation, M.M., H.Y., and R.R.; resources, M.M. and F.T.; data curation, M.M. and H.H.; writing—original draft preparation, M.M.; writing-review and editing, M.M., M.V., F.T., H.H., and T.S.; visualization, M.M., H.Y., R.R., and A.A.B.A.; supervision, M.M. and F.T.; project administration, H.Y.; funding acquisition, M.M. and F.T. All authors have read and agreed to the published version of the manuscript.

Funding: This study was supported by 2019-2021 Basic Research Grants from Ministry of Research, Technology and Higher Education/Ministry of Education, Culture, Research, and Technology (Contract no: T/3/UN.16.17/PT.01.03/PD-Kebencanaan/2019; T/18/UN.16.17/PT.01.03/AMD/PDKebencanaan/2020, and 021/E4.1/AK.04.PT/2021), Universiti Kebangsaan Malaysia grant (GUP2019-035) and Malaysian Ministry of Higher Education Grant (LRGS/1/2020/UKM-UKM/01/6/1).

Institutional Review Board Statement: Not applicable.

Informed Consent Statement: Not applicable.

Data Availability Statement: All data used in this study are available upon request. 
Acknowledgments: Optical Rain Gauges (ORGs) were operated by National Institute of Aeronautics and Space (LAPAN), Shimane University, and Kyoto University under financial support from the Ministry of Education, Culture, Sports, Science, and Technology (MEXT) of Japan. We also thank the National Aeronautics and Space Administration (NASA) for providing IMERG data.

Conflicts of Interest: The authors declare no conflict of interest.

\section{References}

1. Nitta, T.; Mizuno, T.; Takahashi, K. Multi-Scale Convective Systems during the Initial Phase of the 1986/87 El Niño. J. Meteorol. Soc. Japan Ser. II 1992, 70, 447-466. [CrossRef]

2. Marzuki, M.; Hashiguchi, H.; Yamamoto, M.K.; Yamamoto, M.; Mori, S.; Yamanaka, M.D.; Carbone, R.E.; Tuttle, J.D. Cloud episode propagation over the Indonesian Maritime Continent from 10years of infrared brightness temperature observations. Atmos. Res. 2013, 120-121, 268-286. [CrossRef]

3. Marzuki; Hashiguchi, H.; Kozu, T.; Shimomai, T.; Shibagaki, Y.; Takahashi, Y. Precipitation microstructure in different MaddenJulian Oscillation phases over Sumatra. Atmos. Res. 2016, 168, 121-138. [CrossRef]

4. Vincent, C.L.; Lane, T.P. Mesoscale variation in diabatic heating around Sumatra, and its modulation with the Madden-Julian oscillation. Mon. Weather Rev. 2018, 146, 2599-2614. [CrossRef]

5. Mori, S.; Jun-Ichi, H.; Tauhid, Y.I.; Yamanaka, M.D.; Okamoto, N.; Murata, F.; Sakurai, N.; Hashiguchi, H.; Sribimawati, T. Diurnal land-sea rainfall peak migration over Sumatera Island, Indonesian Maritime Continent, observed by TRMM satellite and intensive rawinsonde soundings. Mon. Weather Rev. 2004, 132, 2021-2039. [CrossRef]

6. Yamanaka, M.D. Physical climatology of Indonesian maritime continent: An outline to comprehend observational studies. Atmos. Res. 2016, 178-179, 231-259. [CrossRef]

7. Renggono, F.; Hashiguchi, H.; Fukao, S.; Yamanaka, M.D.; Ogino, S.-Y.; Okamoto, N.; Murata, F.; Sitorus, B.P.; Kudsy, M.; Kartasasmita, M. Precipitating clouds observed by 1.3-GHz boundary layer radars in equatorial Indonesia. Ann. Geophys. 2001, 19, 889-897. [CrossRef]

8. Wu, P.; Hamada, J.I.; Mori, S.; Tauhid, Y.I.; Yamanaka, M.D.; Kimura, F. Diurnal variation of precipitable water over a mountainous area of Sumatra Island. J. Appl. Meteorol. 2003, 42, 1107-1115. [CrossRef]

9. Wu, P.; Hara, M.; Hamada, J.I.; Yamanaka, M.D.; Kimura, F. Why a large amount of rain falls over the sea in the vicinity of western Sumatra Island during nighttime. J. Appl. Meteorol. Climatol. 2009, 48, 1345-1361. [CrossRef]

10. Tan, H.; Ray, P.; Barrett, B.; Dudhia, J.; Moncrieff, M.W. Systematic patterns in land precipitation due to convection in neighboring islands in the Maritime Continent during MJO propagation. J. Geophys. Res. Atmos. 2021, 126, e2020JD033465. [CrossRef]

11. Marzuki, M.; Suryanti, K.; Yusnaini, H.; Tangang, F.; Muharsyah, R.; Vonnisa, M.; Devianto, D. Diurnal variation of precipitation from the perspectives of precipitation amount, intensity and duration over Sumatra from rain gauge observations. Int. J. Climatol. 2021, 41, 4386-4397. [CrossRef]

12. Fukao, S.; Hashiguchi, H.; Yamamoto, M.; Tsuda, T.; Nakamura, T.; Yamamoto, M.K.; Sato, T.; Hagio, M.; Yabugaki, Y. Equatorial Atmosphere Radar (EAR): System description and first results. Radio Sci. 2003, 38, 1053. [CrossRef]

13. Fukao, S. Coupling processes in the equatorial atmosphere (CPEA): A project overview. J. Meteorol. Soc. Japan Ser. II 2006, 84, 1-18. [CrossRef]

14. Yang, G.Y.; Slingo, J. The diurnal cycle in the tropics. Mon. Weather Rev. 2001, 129, 784-801. [CrossRef]

15. Xiao, C.; Yuan, W.; Yu, R. Diurnal cycle of rainfall in amount, frequency, intensity, duration, and the seasonality over the UK. Int. J. Climatol. 2018, 38, 4967-4978. [CrossRef]

16. Suryanti, K.; Marzuki; Muharsyah, R.; Vonnisa, M.; Tangang, F. Diurnal rainfall variability in West Sumatra from rain gauge observation. AIP Conf. Proc. 2020, 2221, 090003.

17. Dai, A.; Giorgi, F.; Trenberth, K.E. Observed and model-simulasted diurnal cycles of precipitation over the contiguous United States. J. Geophys. Res. Atmos. 1999, 104, 6377-6402. [CrossRef]

18. Marzuki, M.; Helmi, Y.; Fredolin, T.; Robi, M.; Mutya, V.; Harmadi, H. Land-Sea Contrast of Diurnal Cycle Characteristics and Rain Event Propagations over Sumatra According to Different Rain Duration and Seasons. Atmos. Res. 2021; final rev.

19. Yin, S.; Chen, D.; Xie, Y. Diurnal variations of precipitation during the warm season over China. Int. J. Climatol. 2009, 29, 1154-1170. [CrossRef]

20. Rajan, D.; Pattnaik, S.; Karunasagar, S. Mean diurnal cycle of monsoon precipitation: Unified model NCUM. Model. Earth Syst. Environ. 2020, 7, 2847-2857. [CrossRef]

21. Tian, B.; Waliser, D.E.; Fetzer, E.J. Modulation of the diurnal cycle of tropical deep convective clouds by the MJO. Geophys. Res. Lett. 2006, 33, L20704. [CrossRef]

22. Mourre, L.; Condom, T.; Junquas, C.; Lebel, T.; Sicart, J.E.; Figueroa, R.; Cochachin, A. Spatio-temporal assessment of WRF, TRMM and in situ precipitation data in a tropical mountain environment (Cordillera Blanca, Peru). Hydrol. Earth Syst. Sci. 2016, 20, 125-141. [CrossRef]

23. Hara, M.; Yoshikane, T.; Takahashi, H.G.; Kimura, F.; Noda, A.; Tokioka, T. Assessment of the diurnal cycle of precipitation over the Maritime Continent simulated by a $20 \mathrm{~km}$ mesh GCM using TRMM PR data. J. Meteorol. Soc. Japan Ser. II 2009, 87, 413-424. [CrossRef] 
24. Tan, J.; Huffman, G.J.; Bolvin, D.T.; Nelkin, E.J. Diurnal Cycle of IMERG V06 Precipitation. Geophys. Res. Lett. 2019, 46, 13584-13592. [CrossRef]

25. Marzuki, M.; Kozu, T.; Shimomai, T.; Randeu, W.L.; Hashiguchi, H.; Shibagaki, Y. Diurnal variation of rain attenuation obtained from measurement of raindrop size distribution in equatorial Indonesia. IEEE Trans. Antennas Propag. 2009, 57, $1191-1196$. [CrossRef]

26. Marzuki; Hashiguchi, H.; Shimomai, T.; Randeu, W.L. Cumulative distributions of rainfall rate over Sumatra. Prog. Electromagn. Res. M 2016, 49, 1-8. [CrossRef]

27. Marzuki; Yoseva, M.; Hashiguchi, H.; Vonnisa, M.; Harmadi; Luini, L.; Nugroho, S.; Muzirwan; Shafii, M.A. Characteristics of Rain Attenuation for Microwave-to-terahertz Waveband from Raindrop Size Distribution Observation in Indonesia. In Proceedings of the Progress in Electromagnetics Research Symposium, Rome, Italy, 17-20 June 2019; Volume 2019.

28. Marzuki; Hashiguchi, H.; Vonnisa, M.; Harmadi; Muzirwan; Nugroho, S.; Yoseva, M. Z-R Relationships for Weather Radar in Indonesia from the Particle Size and Velocity (Parsivel) Optical Disdrometer. In Proceedings of the Progress in Electromagnetics Research Symposium, Toyama, Japan, 1-4 August 2018; Volume 2018.

29. Marzuki; Randeu, W.L.; Kozu, T.; Shimomai, T.; Hashiguchi, H.; Schönhuber, M. Raindrop axis ratios, fall velocities and size distribution over Sumatra from 2D-Video Disdrometer measurement. Atmos. Res. 2013, 119, 23-37. [CrossRef]

30. Optical Rain Gauge. Available online: http:/ / www.opticalscientific (accessed on 11 November 2021).

31. Kozu, T.; Shimomai, T.; Akramin, Z.; Marzuki; Shibagaki, Y.; Hashiguchi, H. Intraseasonal variation of raindrop size distribution at Koto Tabang, West Sumatra, Indonesia. Geophys. Res. Lett. 2005, 32, L07803. [CrossRef]

32. Marzuki, F.; Kozu, T.; Shimomai, T.; Hashiguchi, H.; Randeu, W.L.; Vonnisa, M. Raindrop size distributions of convective rain over equatorial Indonesia during the first CPEA campaign. Atmos. Res. 2010, 96, 645-655. [CrossRef]

33. Shibagaki, Y.; Kozu, T.; Shimomai, T.; Mori, S.; Murata, F.; Fujiyoshi, Y.; Hashiguchi, H.; Fukao, S. Evolution of a super cloud cluster and the associated wind fields observed over the Indonesian maritime continent during the first CPEA campaign. $J$. Meteorol. Soc. Japan Ser. II 2006, 84, 19-31. [CrossRef]

34. Kozu, T.; Reddy, K.K.; Mori, S.; Thurai, M.; Ong, J.T.; Rao, D.N.; Shimomai, T. Seasonal and diurnal variations of raindrop size distribution in Asian monsoon region. J. Meteorol. Soc. Japan 2006, 84, 195-209. [CrossRef]

35. Madden-Julian Oscillation (MJO). Available online: http://www.bom.gov.au/climate/mjo/ (accessed on 11 November 2021).

36. Aldrian, E.; Susanto, R.D. Identification of three dominant rainfall regions within Indonesia and their relationship to sea surface temperature. Int. J. Climatol. 2003, 23, 1435-1452. [CrossRef]

37. Yu, R.; Xu, Y.; Zhou, T.; Li, J. Relation between rainfall duration and diurnal variation in the warm season precipitation over central eastern China. Geophys. Res. Lett. 2007, 34, L13703. [CrossRef]

38. Huffman, G.J.; Bolvin, D.T.; Braithwaite, D.; Hsu, K.-L.; Joyce, R.J.; Kidd, C.; Nelkin, E.J.; Sorooshian, S.; Stocker, E.F.; Tan, J Integrated multi-satellite retrievals for the Global Precipitation Measurement (GPM) mission (IMERG). In Satellite Precipitation Measurement; Springer: Cham, Germany, 2020; pp. 343-353.

39. Wang, J.; Petersen, W.A.; Wolff, D.B. Validation of satellite-based precipitation products from TRMM to GPM. Remote Sens. 2021, 13, 1745. [CrossRef]

40. Ratna, S.B.; Ratnam, J.V.; Behera, S.K.; Tangang, F.T.; Yamagata, T. Validation of the WRF regional climate model over the subregions of Southeast Asia: Climatology and interannual variability. Clim. Res. 2017, 71, 263-280. [CrossRef]

41. Hong, S.-Y.; Dudhia, J.; Chen, S.-H. A revised approach to ice microphysical processes for the bulk parameterization of clouds and precipitation. Mon. Weather Rev. 2004, 132, 103-120. [CrossRef]

42. Chen, F; Dudhia, J. Coupling an advanced land surface-hydrology model with the Penn State-NCAR MM5 modeling system. Part I: Model implementation and sensitivity. Mon. Weather Rev. 2001, 129, 569-585. [CrossRef]

43. Betts, A.K.; Miller, M.J. A new convective adjustment scheme. Part II: Single column tests using GATE wave, BOMEX, ATEX and arctic air-mass data sets. Q. J. R. Meteorol. Soc. 1986, 112, 693-709.

44. Janjić, Z.I. The step-mountain eta coordinate model: Further developments of the convection, viscous sublayer, and turbulence closure schemes. Mon. Weather Rev. 1994, 122, 927-945. [CrossRef]

45. Mlawer, E.J.; Taubman, S.J.; Brown, P.D.; Iacono, M.J.; Clough, S.A. Radiative transfer for inhomogeneous atmospheres: RRTM, a validated correlated-k model for the longwave. J. Geophys. Res. Atmos. 1997, 102, 16663-16682. [CrossRef]

46. Dudhia, J. Numerical study of convection observed during the winter monsoon experiment using a mesoscale two-dimensional model. J. Atmos. Sci. 1989, 46, 3077-3107. [CrossRef]

47. Xu, R.; Tian, F.; Yang, L.; Hu, H.; Lu, H.; Hou, A. Ground validation of GPM IMERG and TRMM 3B42V7 rainfall products over southern Tibetan Plateau based on a high-density rain gauge network. J. Geophys. Res. Atmos. 2017, 122, 910-924. [CrossRef]

48. Yusnaini, H.; Ramadhan, R.; Marzuki, M.; Ningsih, A.P.; Hashiguchi, H.; Shimomai, T.; Vonnisa, M.; Harmadi, H.; Suryanto, W.; Sholihun, S. Statistical Comparison of IMERG Precipitation Products with Optical Rain Gauge Observations over Kototabang, Indonesia. J. Ilmu Fis. Univ. Andalas 2022, 14, 10-20.

49. Tang, S.; Li, R.; He, J.; Wang, H.; Fan, X.; Yao, S. Comparative evaluation of the GPM IMERG early, late, and final hourly precipitation products using the CMPA data over Sichuan Basin of China. Water 2020, 12, 554. [CrossRef]

50. Hilario, M.R.A.; Olaguera, L.M.; Narisma, G.T.; Matsumoto, J. Diurnal characteristics of summer precipitation over Luzon Island, Philippines. Asia-Pac. J. Atmos. Sci. 2020, 57, 573-585. [CrossRef]

51. Waliser, D.E.; Gautier, C. A satellite-derived climatology of the ITCZ. J. Clim. 1993, 6, 2162-2174. [CrossRef] 
52. Yuan, W.; Yu, R.; Chen, H.; Li, J.; Zhang, M. Subseasonal characteristics of diurnal variation in summer monsoon rainfall over central eastern China. J. Clim. 2010, 23, 6684-6695. [CrossRef]

53. Seto, T.H.; Yamamoto, M.K.; Hashiguchi, H.; Fukao, S. Convective activities associated with intraseasonal variation over Sumatera, Indonesia, observed with the equatorial atmosphere radar. Ann. Geophys. 2004, 22, 3899-3916. [CrossRef]

54. Lafleur, D.M.; Barrett, B.S.; Henderson, G.R. Some climatological aspects of the Madden-Julian Oscillation (MJO). J. Clim. 2015, 28, 6039-6053. [CrossRef]

55. Suzuki, T. Diurnal cycle of deep convection in super clusters embedded in the Madden-Julian Oscillation. J. Geophys. Res. Atmos. 2009, 114, D22102. [CrossRef] 